\title{
INVESTIGATION PROTOCOLS FOR DATING DEFENCE ARCHITECTURE
}

\author{
D.R. FIORINO, C. GIANNATTASIO, S.M. GRILLO, \& V. PINTUS \\ DICAAR, Department of Civil - Environmental Engineering and Architecture, \\ University of Cagliari, Italy
}

\begin{abstract}
This article was instigated by an awareness of the complete absence of studies aimed at dating both monumental and minor historical architectures in Sardinia. This situation led us to begin our research with the analysis of fortified systems, such as urban and suburban walls, castles, fortresses, bunkers, and defence and lookout towers. These systems were chosen because they are usually in a rather precarious condition, which greatly facilitates the analysis of masonry structures, both in elevation and in sections. Furthermore, they are generally philologically dated and may therefore represent a benchmark for dating other architectures, particularly 'minor' structures, which are otherwise difficult to be placed chronologically. The research, which is still in progress, is based on a multidisciplinary approach that includes the representation of historical architecture, the architectural history, the stratigraphy of the masonries and analysis techniques. From a construction point of view, the dimensions and materials used are also being investigated, with particular attention to the mineralogical and petrographic characteristics of the components. Following the collection of data through archaeometric and other investigations, management of the data plays a key role in the definition of chronological classes for similar construction techniques.

Keywords: archaeometry, chronology, fortified systems, masonry.
\end{abstract}

\section{SYSTEM FOR DATING DEFENCE ARCHITECTURE}

\subsection{Existing studies $(\mathrm{CG})$}

Studies on traditional masonry construction techniques in Sardinia, and particularly those aimed at dating historical architectures, are somewhat insufficient [1]. This lies in contrast to the studies produced in other national districts, where numerous experiments have been carried out by experts in the fields of medieval and post-medieval archaeology, applying the methods of stratigraphy, since the 1970s. In Sardinia, in fact, there are no systematic records of the constructive solutions adopted between the Middle Ages and the early 20th century for the construction of masonry structures. Studies related to the history of the structures are in fact rather scarce [2-5] or mainly focused on the historical and architectural aspects [6, 7] or on typological and structural engineering [8-11]. Over the last decade, this context has led the Restoration Committee at the Faculty of Architecture in Cagliari to conduct research designed to fill this knowledge gap, which focuses on the chronotypological definition of masonry structures, based on archaeometrical surveys [12-14]. 
1.2 Sardinian defence systems between the Middle Ages and the 17th century (CG)

The origin and evolution of Sardinian defence systems (Fig. 1) was strongly influenced by the political, administrative structure and developed gradually through the presence of different powers on the same territory: the Sardinian Giudicati, the cities of Pisa and Genoa - with the Donoratico, Massa, Visconti, Malaspina and Doria families - and the Crown of Aragon. As

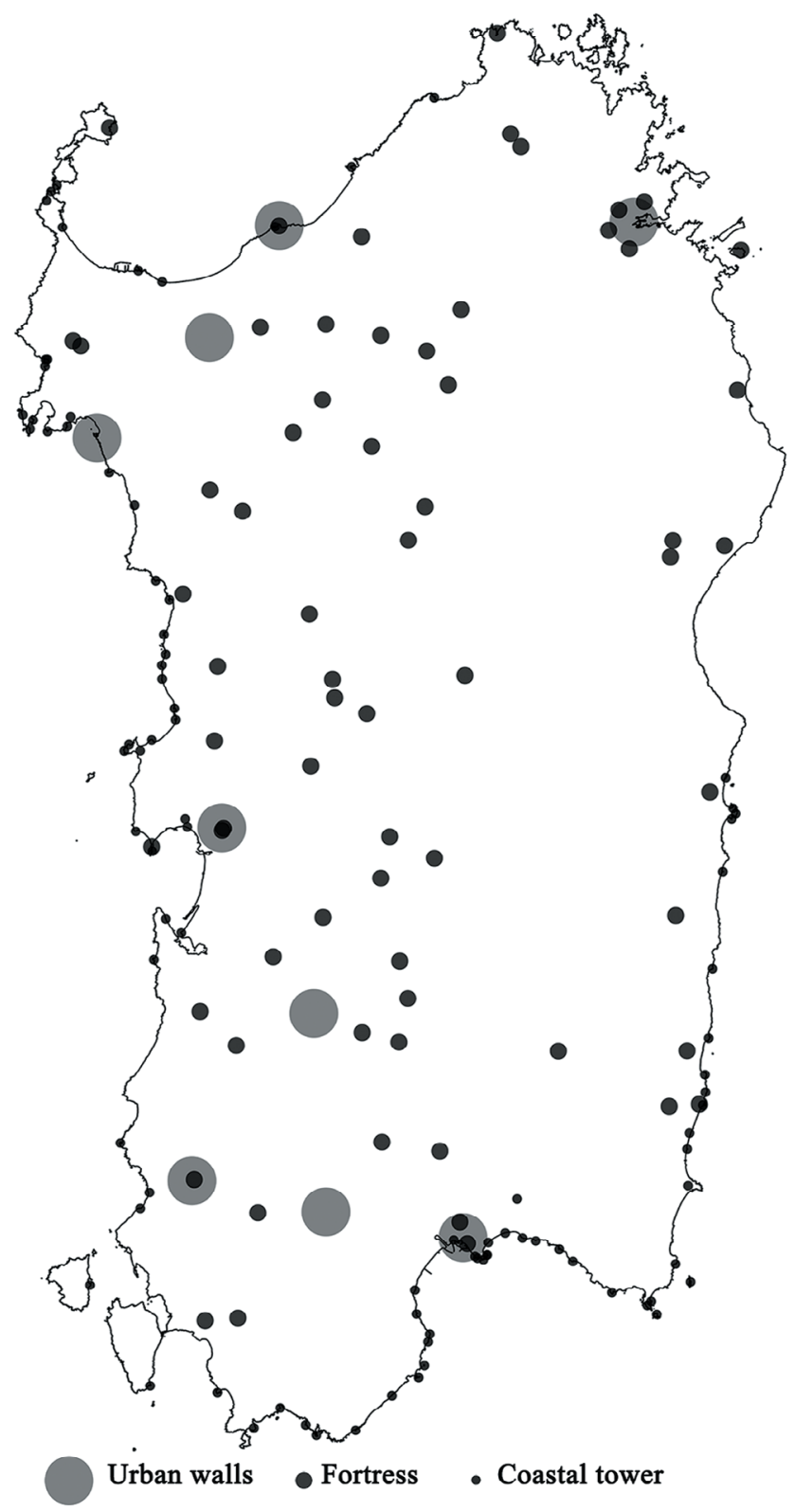

Figure 1: Sardinian defence system: architectural typologies (graphic output from GIS by V. Pintus). 
regards the system of Giudicati, it is important to note that the rise of this institution is one of the most debated issues among local historians, due to a significant lack of documentation. However, it is widely agreed that the Giudicati were formed and developed after the progressive political disengagement of the Byzantine Empire from the island. Consequently, new local political and administrative systems developed. Among such systems were a governmental structure controlled by a $d u x$ - with military functions - and a praeses - with civil and administrative functions [15], and a structure with only a judex provinciae, which had defensive, administrative and governmental authority. This new political situation divided the territory into four partes, then named the Giudicati, with somewhat unstable headquarters in the cities of Caralis, Tharros, Turris and Olbia.

The Arab raids, which continued for at least three centuries, accelerated the depopulation of the island. Some cities retreated inland to areas protected by non-navigable lagoons. This was the case for Cagliari, which moved near Santa Igia, and Tharros basins, and for Oristano, which was founded in the area protected by the large basins of Sassu, Santa Giusta and Cabras. Consequently, in 1016, during a new Saracen attack led by Mugiahid, Prince of Denia, the Maritime Republics of Pisa and Genoa, formed an alliance in an attempt to stop the Arab expansion in the Mediterranean.

The enemy fleet was defeated by the alliance between Pisa and Genoa, and from this moment on, the political and economic merging of the two maritime republics on the island began. They became the beneficiaries of a policy of subsidies and donations created by the Sardinian king; they battled alongside each other, conquering neighbouring kingdoms in an attempt to unify the entire island. Through this system, the two maritime republics acquired military and economic support. They were therefore able to extensively occupy the Sardinian territory in a short time, through the foundation of strongholds and by conquering local communities. The creation of the Regnum Sardiniae et Corsicae, granted by Boniface VIII to James II of Aragon in 1927, set the premise for the military expeditions of the young Alfonso. He landed and conquered Villa di Chiesa (1324) and then took possession of the Pisan Castle of Cagliari (1326). The total and definitive Aragonese conquest of the island occurred only in 1478, at the battle of Macomer, which marked the final failure of numerous attempts at autonomy and the ultimate disappearance of political and administrative system of the Giudicati [16]. The defensive function of the castles became obsolete and, from the 15 th century onwards, many of these structures were turned into private residences or totally abandoned. In particular, the defensive system used by the kingdoms of Calari and Arborea consisted of reusing the existing fortresses and building new fortified structures.

The entire system of coastal towers took at least five centuries to construct (13th-18th centuries), but the fortification of the Sardinian coastline reached its peak in the 16th and 17th centuries, while the island was under the control of the Spanish. When Philip II took the Spanish throne in the latter half of the 16th century (1556), the most significant phase of construction took place, and a truly organic system was created. Turkish victories at La Goulette and Tunisi in 1570 signalled the loss of the Spanish Empire's westernmost outpost in North Africa and the retreat of its defensive front. In this new geopolitical context, Sardinia gained a new strategic role.

The towers, approximately 105 , were built with the main purpose of providing a lookout system. Occasionally, defensive structures were built, exclusively in significant strategic sites. A large number of these towers, that is 51 , are in good condition, thanks also to recent restoration projects carried out by protection authorities; 37 are in an advanced state of degradation and 15 have disappeared. 


\subsection{Investigation Protocol (CG)}

The research project is twofold. On the one hand, it is based on indirect analysis, with the systematic recognition of bibliographic, archival, manualitsic, iconographic and graphic sources. On the other hand, it is centred around direct analyses of the structures in question (Fig. 2) through photographic, metric, architectural and material evaluations, and predominantly non-destructive diagnostic investigations.

The direct analysis phase began with stratigraphic analyses of the contexts, which is preparatory to the choice of samples to be analysed. The phase of gaining direct knowledge of the structure and its context is often rather difficult, given the position of the architectural structures in question. Due to their defensive and lookout functions, their locations are often very difficult to reach. To this end, photogrammetry and photo-straightening software were used to create representations of the towers. In the case of cylindrical structures, truncated cones or escarpments such as the coastal towers, the combined use of direct investigations and photogrammetric techniques based on photo modelling (123D Catch - Autodesk webbased software) yielded particularly effective results. A laser scanner was occasionally used.

This article is based on an 'archaeological' approach, beginning with a typological, morphological, metrological and stratigraphic understanding of the building as a whole (Fig. 3). The structure is then described in detail through graphic representations in plan, elevation and section views and illustrations of the masonry features. In-depth investigations into the structures focus primarily on masonry techniques, with attention to the most structurally stressed parts, such as basements and corners, as well as functional and decorative elements, such as entrances, window frames, string courses, etc. For each structure, the examination focuses on site as a whole, including the presence of building works, horizontal planes recurring at regular intervals, the offset of vertical joints, regularity in the arrangement of the elements, the presence and location of scaffolding holes, and other such features. Subsequently, the article focuses on the individual components: stone elements, joints and plaster layers.

The stones are classified in terms of (a) lithological type and origin; (b) morphological, volumetric and metric characteristics; (c) processing of exposed facades and edges, and (d) presence of distinctive dating signs, such as masonry marks and engravings. Both the vertical and horizontal joints are analysed with particular attention in terms of their size and the
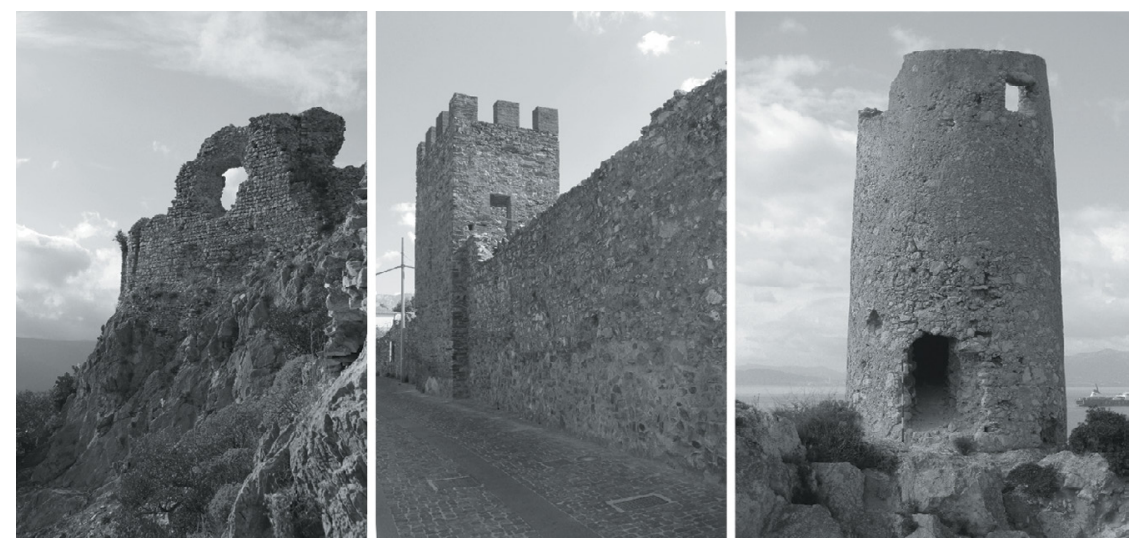

Figure 2: The castle of Quirra in Villaputzu (12th century), the urban wall of Iglesias (13th century) and the coastal tower of Prezzemolo in Cagliari (16th century). 

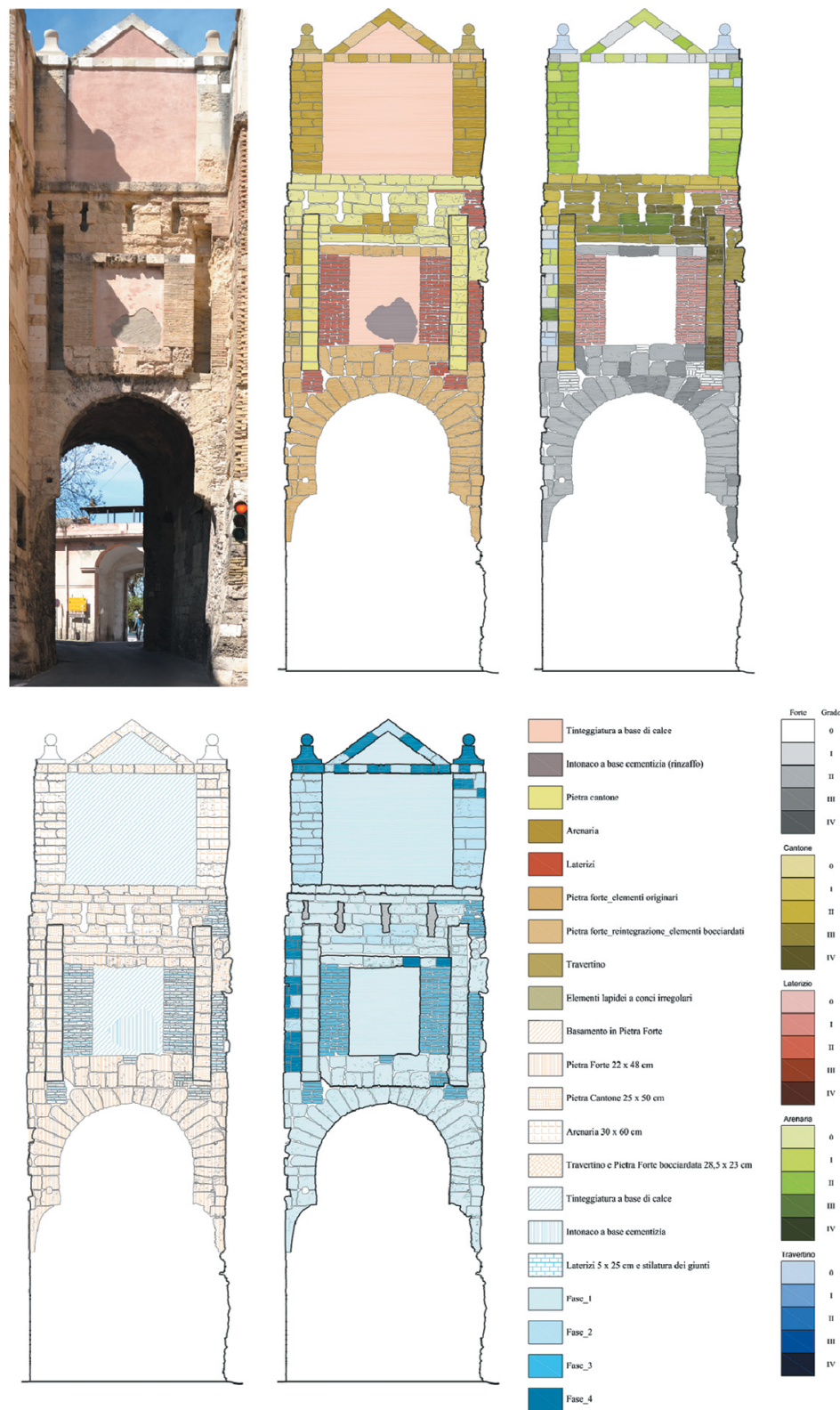

Figure 3: Cagliari urban door called D'Altamira. Integrated study on materials and levels of erosion, building techniques, stratigraphy and restoration works (scientific research by D.R. Fiorino, drawing by A. Manca, D. Orrù, F. Farci and F. Savona).

composition of the mortar. Finally, the article focuses on the plaster, if present, recording the thickness of the layers - rough coat, curl, finishing - and the components of each of them.

The composition of mortar and plaster is generally determined by different analytical methods. The methodology employs a meticulous autoptic examination to define the colour, 
hardness and cohesion of the mortar and also to decide proceedings for sampling. The structural and textural characteristics of the masonry samples are defined through (a) mineralogical and petrographic analysis with optical microscopy in polarized light and X-ray diffraction; (b) chemical analysis in X-ray fluorescence; and (c) size analysis in order to determine the binder/aggregate ratio. Where the execution of repair work compromised the original material, in-depth analysis of any kind is rendered impossible.

By cross-referencing the data on architectural dating, synthesized in specialized graphs and derived from the study of indirect sources and stratigraphic analysis, with the data resulting from the detailed study of the masonry equipment, it is possible to identify specific chronotypes. Graphical and statistical data, relating to the most significant metric and material parameters, support the definition of the chronotypes. For example, through measuring the stone blocks, it is possible to verify the dispersion values or the distribution of the values related to height and width. These values, with typological and morphological aspects, are parametric values. Through comparison, it is possible to chronologically define any structures that are not philologically dated, but those that were built in the same area during the same period.

\subsection{Building materials (SMG)}

Since prehistoric times, stone held great importance not only as a material, but also as a mysterious and esoteric element. Traditionally, it was used for construction, because it is strong and durable. Today, although it is used for different purposes, the charm of stone is unchanged and it is still often used. Its history and its infinite applications are detailed and described in reports and publications. It is possible to understand the close connection between stone and architecture. Furthermore, it can be used to analyse historical buildings such as fortifications, castles and towers, built over the centuries in Sardinia, which is as varied as a continent in lithological terms.

Sardinia has a long geological history, which began more than 600,000 years ago. This led to the formation of a wide variety of rocks. The materials used in architecture vary from city to city, from town to town, and from building to building, according to the most readily available resources in each lithological context and the most advantageous materials in terms of their structural or decorative functions. In this sense, the defensive architectures are emblems that define the historical link between territory and buildings. The types of Sardinian stone most widely used in buildings are granite, volcanic and carbonate stones.

The outcrops of rocks decisively influence different kinds of buildings in different historical ages. Stone structures generally have the same colour and the same characteristics as the local rocky outcrops. This influence is particularly visible in the selection of materials for the construction of coastal forts, city walls, castles, etc. Certainly, the use of local stone resources was unavoidable due to higher costs for large supplies of materials from distant places. These simple but significant structures represent a territorial footprint of the place where they were built. The city walls of Cagliari are different from those in Alghero. In the same way, the Castle of Burgos is different from that of Bosa or Cuglieri, and the towers of Sinis are different from those of Bosa or Cagliari. It is therefore evident that this diversity in construction is not only the result of the work of various craftsmen, but it is strongly influenced by the physical, chemical, mineralogical and petrographic characteristics of local stone outcrops. The systematic and comparative study of all natural and artificial stone materials used in historical architectures, and consequent knowledge of them, is fundamental and must 
be present in this protocol. In fact, it must surely form the basis of all conservation operations in historical architectural heritage.

The aim of the material surveys is to define the mineralogical and petrographic nature of the stones, plaster and mortar and to define the binders and aggregates, as well as any alteration of the mineral components. It is necessary to compare the lithological nature of the stones with geological and lithological characteristics of the area in which the buildings were constructed in order to verify any possible supplies of foreign materials. Autoptic investigations carried out on site and archaeometrical analysis, such as optical microscopy, $\mathrm{X}$-ray diffraction and fluorescence, microscopy and electronic microanalysis, allow for an exhaustive characterization of natural and artificial stones (Fig. 4). This in turn permits us to define their mineralogical and petrographic composition and their state of decay to carry out detailed systematic collection of data (stones/degradation) related to dating and to guide an appropriate conservation project, where necessary.

\subsection{Stratigraphy and interfaces (DRF)}

The stratigraphic analysis of the structures, which is already widely codified in terms of methodology and operational protocols, represents the synthesis of the knowledge process and the interpretation of the material signs conserved by the structure in relation to its long history [16, 17].

Sardinia's patrimony of defensive structures presents a notably layered character. This fact can be primarily attributed to the strategic position in which the structures were built; it led, over time, to the persistent use of many settlements, albeit with adaptations made to the structures, in order to suit the changing nature of offence and defence [14]. The history of these transformations is still visible in the variation of the building techniques adopted, in the layering, in the demolitions and in the maintenance works that have left material traces on the buildings that can still be investigated. At the same time, where a site lost its purpose as a military lookout post, in most cases the buildings were abandoned and were gradually reduced to ruins, or in some cases, disappeared completely. The investigation protocol that has already been introduced dedicated great attention to stratigraphic research, divided into
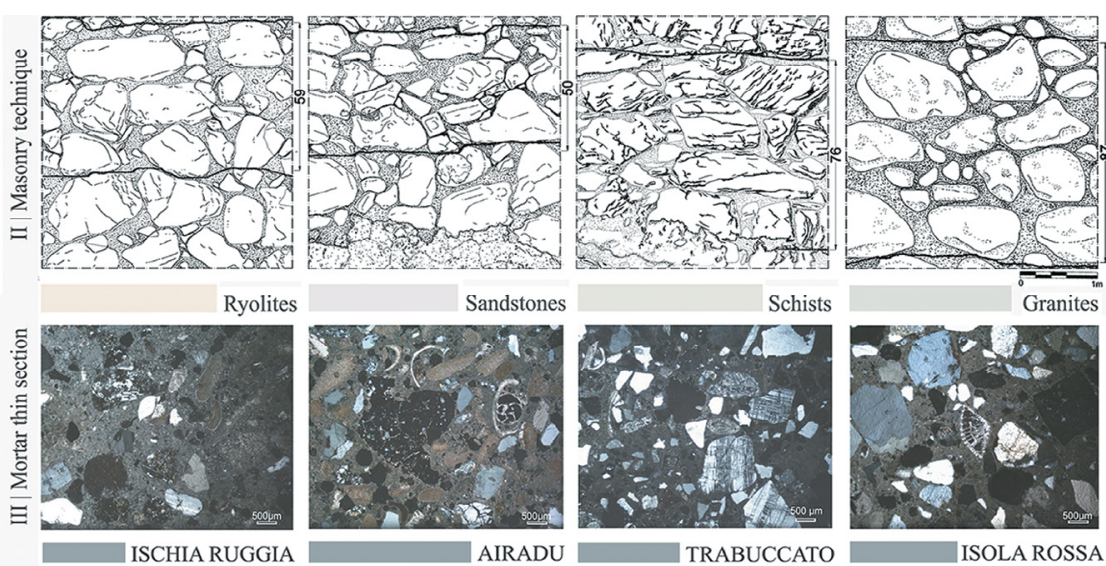

Figure 4: Coast towers system: masonry techniques and thin sections of mortars (drawing by S. Murru). 
the following phases of investigation and interpretation: identification of stratigraphic units (SU) and their detailed metric, material and technological description with the support of record synthesizing apparatus; study of interfaces and stratigraphic relationships between the parties; construction of a Harris diagram with the relevant chronology; and absolute dating of the structures with the support of a simultaneous historical and archival research investigation.

The quality of the investigation was a determining factor in the process of defining the perimeters of the SU. It was conducted on an archaeological basis and was a good quality analysis of construction techniques, which focused particularly on the dimensional analysis of the stone elements, on works carried out on the surface of the blocks, on the size and nature of the joints, and on the definition of the mortar and plaster. This latter aspect is important from a chronological viewpoint; in fact, in military factories, the practice of reusing materials was rather frequent. As a result, masonries that are quite similar in terms of their nature and the size of the individual stone elements they use can instead be attributed to different chronological phases due to the variation in the mortar used to join them, which acts as material evidence of a disassembling and reassembling process.

The most significant instances of stratigraphic analysis were conducted on the city walls of Cagliari [18], because there is a reason to believe that there is a direct correspondence between the construction techniques used in the building of the defensive walls and those found in the main religious monuments of the city. The 'archaeological viewpoint', whose physical dimension was extended to include the newer layers, focused on the recognition and analysis of the SU of integration, namely those derived from restoration activities aimed at resolving the heavy erosion of the calcarenite stone, manifested over time (Fig. 3).

The integration of the architectural lacuna in the case of the walls of Cagliari was made with different materials and shapes. As such, it is an important dating element, demonstrating the different integration methods used from the last quarter of the 19th century onwards. The dating of these events will allow, through a process of analogy, the dating of many other masonry structures that can still be seen in numerous sections of the city walls.

A final aspect concerns the interfaces [19], which refer to the physical locations (points, areas or surfaces) in which two qualitatively different entities (SU) come into contact, causing problems regarding connection, transmission, material compatibility, chemical/physical nature, aesthetic and shape or technological nature (structural, thermal, hygrometric). The interface demonstrates a discontinuity in the materials and is therefore a significant element in the chronological reconstruction of the artefacts. It is also the surface of interaction between the 'traditional' materials and stratigraphy and the 'restoration' materials and stratigraphy. The latter, more modern aspect results in a 'physical joint' of overlap and connection that becomes a 'time interface' between ancient materials and the more modern intervention. It demonstrates the degree of sustainability of the transformation process connected to the restoration project. For this reason, it is essential that the restoration work ensures the maximization of the interfaces, as they are the only physical element to demonstrate the growth/decline/ transformation of the historic structures, minimizing the loss of readability. Homogenization of the materials and the use of general coatings at the edges of the interface should therefore be avoided. Similarly, in the context of integration interventions, any new interfaces and new 'edges' which were created using recognizable techniques, yet which are compatible in terms of their technological and aesthetical aspects, should be differentiated and marked out.

The treatment of the lacuna in the restoration underlines the importance of stratigraphic studies, not only in terms of dating the masonry, but also as indispensible prerequisite knowledge to carry out a restoration project [20]. It also encourages reflection on how best to 
reconstruct the ruins and interpret the lacunae, which are negative SU, whose integration should be conservative, in keeping with the profile of stratigraphic recognition, both aesthetically and technologically sustainable, compatible, reliable and reversible in terms of materials and features.

\section{A CASE STUDY: THE CASTLE OF GIOIOSA GUARDIA IN VILLAMASSARGIA}

(VP)

The Castle of Gioiosa Guardia in Villamassargia (Sardinia) is a classic example of a 13thcentury military fortress (Fig. 5) [21]. It was located in a strategic position on top of a hill with the same name. It guarded and watched over the Cixerri valley, which was important due to its rich mineral resources. The fortress, which was built to comply with the features of the landscape, spreads over several levels. Halfway along the southern side are the ruins of buildings that very probably served as guardhouses. On top of the hill are the ruins of the castle itself, enclosed and protected by a perimetral curtain wall, along with the ruins of various service rooms and three tanks.

The tanks are made of bricks and plaster, while the rest of the architectural complex is a stone structure, in which the local rocks were cut into square blocks in the corners and in the air currents for the walls. Currently there are no reliable sources regarding the foundation of Gioiosa Guardia castle. The most likely hypothesis states that it was built in the late 13th century, when the territory formerly owned by the Giudicato of Cagliari was divided into three parts. Gioiosa Guardia castle is located in the third section and was assigned to Count Donoratico of the Gherardesca family. This hypothesis is quite plausible, since, in addition to the absence of any mention of the castle in documents prior to the 13th century, its position provides important, useful insights in terms of defining its original function and understanding the historical events that affected it. Documentary sources clearly attest that in the beginning of the 16th century, the castle was abandoned and its condition already appeared to be precarious.

The aim of this case study is to define the construction techniques used to build the fortress, which was made at the request of the Gherardesca family of Pisa. It was built in a single

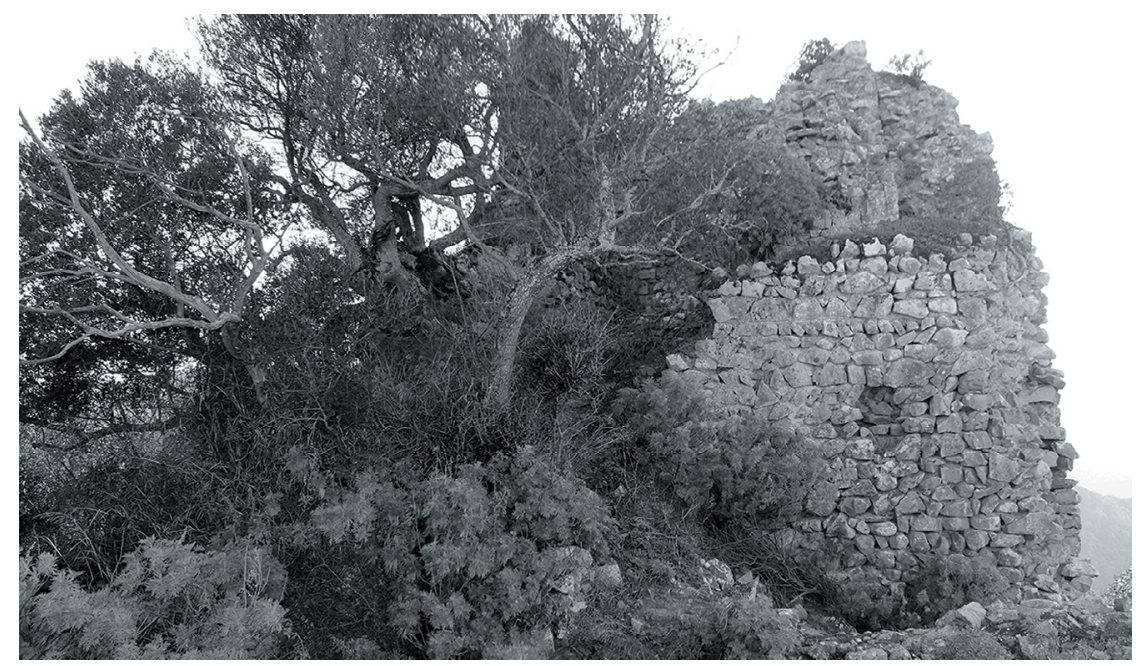

Figure 5: Villamassargia (Cagliari), the Castle of Gioiosa Guardia, facade N-E. 
phase and was abandoned after just two centuries. It uses a Pisan wall structure, which was employed in Sardinia in the late 13th century.

The chronotypological definition of the walls was carried out using an interdisciplinary method, through an archaeometric analysis developed over three main phases: photogrammetric surveys; archaeological investigation - underlying the formal, dimensional and technological aspects - and, finally, a mineralogical and petrographic characterization of the natural and artificial stone materials, through the analysis of thin sections.

\subsection{Architectural features}

The complex was built in a dominating position, in accordance with the morphology of the territory, using stone that was flattened with the specific purpose of facilitating its construction. The castle consists of several parts: the fortress, surrounded entirely by a curtain wall and built on top of the hill, and other buildings, which are difficult to define and are located halfway up the southern slope. The tower, built directly on the outcrop of rock, is currently the only recognizable section of the ruins. Its corners are oriented towards the four cardinal points. It is easy to distinguish the perimeter walls, but there is no trace of the roof or floor slabs. The tower is rectangular in shape with dimensions of $2.85 \times 5.80 \mathrm{~m}$ below $3 \mathrm{~m}$ in height, and of $3.15 \times 6.05 \mathrm{~m}$ above $3 \mathrm{~m}$. The thickness of the walls is $55 \mathrm{~cm}$ ( 2 spans). Its thickness is detectable near the east angle due to the collapse of the masonry. The thickness of walls was doubled to reinforce the structure; an exterior wall was constructed, which was separated from the inner wall by a cavity. We can assume that the tower did not originally have the external wall as reinforcement, which was built using a similar masonry technique. Inside, it is easy to interpret the stratigraphy of the structures: the four walls were built at the same time, a fact which is made evident by the uniformity that characterized the masonry structure. It is guided by the height of ashlars at the four corners, where the masonry is held together firmly.

\subsection{Defining masonry chronotypes}

The application of archaeometrical analysis allowed the definition of two wall chronotypes, both of which date back to the end of the 13th century.

The walls of the fortress were built using the same masonry technique and the same materials: limestone, andesite and lime mortar. The stones were sourced locally. In particular, the andesitic rock has a volcanic origin and was very probably extracted from a local quarry, located on the western side of the hill on which the castle is situated. The limestone is also present in the surrounding area. Elements of re-use are completely absent, which confirms the hypothesis that the castle is a completely new building. Square blocks of yellowish white limestone were used to add detail at the corners. The andesitic rocks, which are greyish green in colour, are irregular in shape but have a smooth exterior facade. They were used to build the walls. The masonry is composed of two parallel walls and a central cavity filled with small chippings and stone fragments, and is covered in lime mortar with coarse aggregates. The andesitic blocks are medium and small in size. They are arranged in horizontal rows, the height of which follows that of the limestone blocks at the corners. This regular pattern is maintained using wedges, in a horizontal position, made of the same material. The wall system is completed with the use of mortar with a crumbly consistence and characterized by numerous extra elements, such as small river stones and quartz and schist pebbles. The petro-mineralogical interpretation of the materials, obtained through analyses of thin 

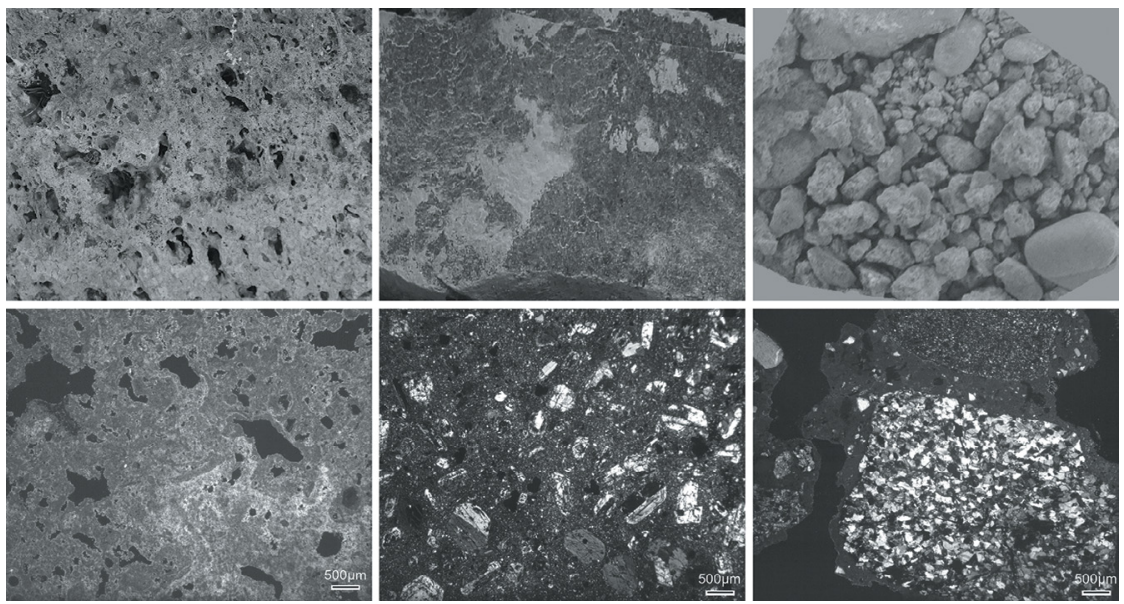

Figure 6: Hand samples of limestone, andesite and plaster and microphotos of correspondent thin sections.

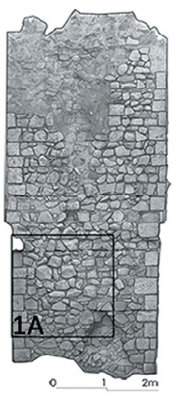

Front SW

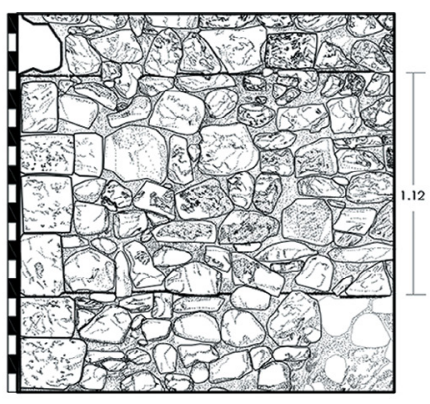

Chrono-type $1 \mathrm{~A}$

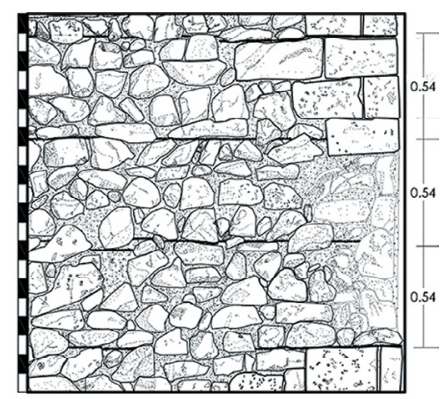

Chrono-type 1B

Figure 7: Defining masonry chronotypes: 1A dating 1270/80; 1B dating 1290/95 (drawing by V. Pintus).

sections, showed that the porphyritic andesite contains phenocrysts of plagioclase (white grey) and amphibole (brightly coloured hornblende) in a fine-grained groundmass. Also, the concretional limestone has a micritic texture and many holes. The thin section of the mortar shows a bimodal grain size distribution of the aggregate, with coarser grains of quartzites and volcanic rocks and smaller grains of monocrystalline quartz and feldspar, and an airhardening calcitic lime binder with a micritic texture (Fig. 6).

The masonry technique used inside the fortress is characterized by sub-horizontal rows of andesitic blocks at the same height as the calcarenite limestone blocks. After exactly four rows, it is possible to recognize a flattened plane, and the distance between two of them is $1.12 \mathrm{~m}$ (approximately 2 feet in the historical metrology system). The heights of the limestone blocks measure 26-27 cm on average, with a maximum height of $34 \mathrm{~cm}$ and a minimum of $19 \mathrm{~cm}$. (chronotype 1A - dating back to the end of the 13th century, 1270-1280). The exterior masonry technique used to reinforce the fortress is characterized by the same technique, but is less regular, with different metrical measurements. As in the previously 
described 1A chronotype, the sub-horizontal rows of andesitic rocks follow the heights of limestone blocks.

The main difference is the position of the flattened plane, which is located after three rows; the distance between these two planes is $54 \mathrm{~cm}$ (approximately 1 foot in historical metrology system). The rows have a greater dimensional variability in height, but due to the collapses that have affected the exterior corners, reading and interpreting the masonry technique is more difficult. The average height of the blocks is lower than that of the chronotype $1 \mathrm{~A}$ blocks. The height of the rows varies from a maximum of $24 \mathrm{~cm}$ to a minimum of $13 \mathrm{~cm}$, and the average value is $17 * 18 \mathrm{~cm}$. (chronotype $1 \mathrm{~B}$ - dating back to the late 13 th century, 1290/95) (Fig. 7).

\section{CONCLUSIONS}

In conclusion, the studies in progress are facilitating the definition of an effective record of construction techniques used to build wall structures within the time period in question. It constitutes a significant point of comparison for the dating of other architectural structures that are not easily placed within a specific historical period. This concept is particularly true for 'minor architecture', for which no historical documentation can generally be found. This type of architecture is built in an economic budget, and as such it is generally devoid of formal elements, which, if carefully preserved, are useful facilitators in the dating process. Precisely because of the lack of recognition of the historical and documentary value of these structures, they are very often the subject of inappropriate demolition work.

Thus, a deeper knowledge of traditional construction techniques can certainly be a valuable tool in guaranteeing their preservation, despite the current paucity of thematic studies with regard to Sardinia. In addition, this cognitive apparatus aims to lead towards the definition of guidelines to ensure the implementation of restoration operations that are firmly based on a sound knowledge of the structure. Such operations therefore offer more appropriate directions in each specific situation, in accordance with the principles of reversibility, distinctiveness, authenticity, minimal intervention and compatibility, which can be transformed into regulations.

\section{REFERENCES}

[1] Giannattasio, C., Lo stato dell'arte sullo studio delle tecniche costruttive in Sardegna. Lo studio delle tecniche costruttive storiche: stato dell'arte e prospettive di ricerca, ed. V. Pracchi, Nodo: Como, pp. 53-57, 2008.

[2] Frulio, G., Applicazione e risultati della lettura metrologica su alcuni edifici bassomedievali della Sardegna. Alétes: miscellanea per i settant'anni di Roberto Caprara, ed. P.L. Abatangelo, Archeogruppo: Massafra, pp. 247-256, 2000.

[3] Milanese, M. ed., Vita e morte dei villaggi abbandonati tra Medioevo ed Età Moderna (Atti del convegno, Sassari-Sorso, 28-29 maggio 2001). All'insegna del giglio: Borgo S. Lorenzo, 2006.

[4] Putzu, M.G., Tecniche costruttive murarie medievali. La Sardegna. L’Erma di Bretschneider: Roma, 2015.

[5] Urgu, A., Le chiese rurali del nord-ovest della Sardegna. Il contributo dell'archeologia dell' architettura nello studio dei villaggi medievali scomparsi. Medioevo in formazione. Tra ricerca e divulgazione (Atti del convegno, Somma Lombardo, 10-13 ottobre, 2013), eds. A. Luongo \& M. Paperini, Debatte: Livorno, pp. 78-87, 2014. 
[6] Coroneo, R., Architettura romanica dalla metà del Mille al primo '300. Ilisso: Nuoro, 1993.

[7] Segni Pulvirenti, F. \& Sari, A., Architettura tardogotica e d'influsso rinascimentale. Ilisso: Nuoro, 1994.

[8] Fois, F., Castelli della Sardegna medievale. Arkadia: Cagliari, 2012.

[9] Montaldo, G., Le torri costiere della Sardegna. Delfino: Sassari, 1992.

[10] Rassu, M., Sentinelle del mare. Le torri della difesa costiera della Sardegna. Grafiche del Parteolla: Dolianova, 2005.

[11] Sanna, A. et al. eds., Manuali del recupero dei centri storici della Sardegna. DEI: Roma, 2009.

[12] Giannattasio, C. \& Pintus, V., Il complesso claustrale di San Francesco a Stampace in Cagliari. Archeologia dell'architettura per il progetto di restauro. Arkos, 3-4(V), pp. 51-72, 2013.

[13] Giannattasio, C., Grillo, S.M. \& Pirisino, M.S., The Rectorate building of the University of Cagliari (18th-20th century): archaeometric analysis of masonries. Arkos, 9-10(V), pp. 31-52, 2015.

[14] Fiorino, D.R. \& Pintus, M., eds., Verso un atlante dei sistemi difensivi della Sardegna, Giannini: Napoli, 2015.

[15] Brigaglia, M., Mastino A. \& Ortu, G.G., Storia della Sardegna. Laterza: Roma, 2002.

[16] Harris, E., Principle of Archaeological Stratigraphy, Academic Press: London, 1979.

[17] Doglioni, F., Stratigrafia e restauro. Tra conoscenza e conservazione dell'architettura, Lint: Trieste, 1997.

[18] Fiorino, D.R., Stratigraphic evidence in the ancient urban walls of Cagliari (SardiniaItaly). Defence Sites II. Heritage and Future, eds. C. Brebbia \& C. Clark, WIT Transactions on the Built Environment: Southampton, Vol. 143, pp. 257-268, 2014.

[19] Fiorino, D.R., Stratigraphy and analysis of interfaces for the preservation of architectural heritage. International Journal of Sustainable Development and Planning, 10(5), WIT Press: Southampton, pp. 755-766, 2015.

[20] Quendolo, A., Permanenza e leggibilità dei dati materiali: alcune riflessioni sul ruolo della conoscenza stratigrafica per la conservazione del potenziale informativo del costruito. Archeologia dell'Architettura n. XI, All'insegna del giglio: Firenze, pp. 1-8, 2006.

[21] Deiana, A.P., Il Castello di Gioiosa Guardia: fonti e testimonianze archeologiche. S'Aluvre: Oristano, 2003. 